\title{
Philosophiques
}

\section{Livres reçus (automne 2009)}

Volume 36, numéro 2, automne 2009

Edmund Husserl (1859-1938)

URI : https://id.erudit.org/iderudit/039491ar

DOI : https://doi.org/10.7202/039491ar

Aller au sommaire du numéro

Éditeur(s)

Société de philosophie du Québec

ISSN

0316-2923 (imprimé)

1492-1391 (numérique)

Découvrir la revue

Citer ce document

(2009). Livres reçus (automne 2009). Philosophiques, 36(2), 647-648.

https://doi.org/10.7202/039491ar

Ce document est protégé par la loi sur le droit d'auteur. L'utilisation des services d'Érudit (y compris la reproduction) est assujettie à sa politique d'utilisation que vous pouvez consulter en ligne.

https://apropos.erudit.org/fr/usagers/politique-dutilisation/
Cet article est diffusé et préservé par Érudit.

Érudit est un consortium interuniversitaire sans but lucratif composé de l’Université de Montréal, l'Université Laval et l'Université du Québec à Montréal. Il a pour mission la promotion et la valorisation de la recherche. https://www.erudit.org/fr/ 


\section{Livres reçus (automne 2009)}

Ameline, Claude, Traité de la volonté, précédé de L'Art de viure heureux (attr. C. Ameline), édition, introduction et notes par Sébastien Charles, Paris, Vrin (coll. «Textes cartésiens en langue française»), 2009, 294 p.

Belna, Jean-Pierre, Histoire de la théorie des ensembles, Paris, Ellipses (coll. "L'esprit des sciences»), 2009, 125 p.

Biemel, Walter, Écrits sur la phénoménologie, Bruxelles, Éditions Ousia, 2009, 353 p.

Bolzano, Bernard, De la méthode mathématique et correspondance Bolzano-Exner, traduction coordonnée par Jan Sebestik et Carole Maigné, Paris, Vrin (coll. «Textes philosophiques»), 2008, 256 p.

Brandom, Robert, Between Saying and Doing: Towards an Analytic Pragmatism, Oxford, Oxford University Press, 2008, 251 p.

De Koninck, Charles, Euvres de Charles de Koninck. Tome I. Philosophie de la nature et des sciences, volume 1, avec un avant-propos de Thomas de Koninck et une présentation d'Yves Larochelle, Québec, Les Presses de l'Université Laval, 2009, 475 p.

Fabry, Jacques, Visions de l'Au-delà et tables tournantes. Allemagne, XVIII-XIX ${ }^{e}$ siècles, Paris, Presses Universitaires de Vincennes (coll. "La philosophie hors de soi »), 2009, 300 p.

Giroux, Dalie, Lemieux, René, Chénier, Pierre-Luc (dir.), Contr'hommage pour Gilles Deleuze. Nouvelles lectures, nouvelles écritures, Québec, Les Presses de l'Université Laval, 2009, 234 p.

Husser, Anne-Claire, Bruno Barthelmé et Nicolas (Piqué, dir.), Les sources de la morale laïque. Héritage croisés, Lyon, ENS Éditions (coll. "La croisée des chemins»), 2009, 134 p.

Kukla, Rebecca, et Mark Lance. 'Yo! and Lo!' The Pragmatic Topography of the Space of Reasons, Cambridge (Mass.), Harvard University Press, 2009, 239 p.

Lavigne, Jean-François, Accéder au transcendantal? Réduction et Idéalisme transcendantal dans les Idées I de Husserl, Paris, Vrin (coll. «Problèmes et Controverses »), 2009, $334 \mathrm{p}$.

Lavigne, Jean-François (dir.), Les méditations cartésiennes de Husserl, Paris, Vrin (coll. «Études et Commentaires»), 2008, 220 p.

Schwarz, Gerhard, Est Deus in Nobis. Die Identität von Gott und reiner praktischer Vernunft in Immanuel Kants Kritik der praktischen Vernunft, Berlin, Verlag TU Berlin, 2004, 307 p.

Stanguennec, André, Être, soi, sens. Les antécédences herméneutiques de la "dialectique réflexive», Villeneuve d'Ascq, Presses Universitaires du Septentrion (coll. "Savoirs et systèmes de pensée»), 2008, 311 p.

Stumpf, Carl, Über die Grundsätze der Mathematik, édition par Wolfgang Ewen, Würzburg, Königshausen \& Neumann, 2008, 180 p.

Vautrelle, Hervé, Qu'est-ce que la violence?, Paris, Vrin (coll. "Chemins philosophiques»), 2009, $128 \mathrm{p}$.

Vendrell Ferran, Ingrid, Die Emotionen. Gefühle in der realistischen Phänomenologie, Berlin, Akademie Verlag (coll. «Philosophische Anthropologie»), 2009, 273 p. 
Outre les ouvrages qui apparaissent dans cette liste, la rédaction de Philosophiques peut obtenir, pour fin de compte rendu ou d'étude critique, la plupart des livres parus récemment.

Les personnes désireuses de faire un compte rendu ou une étude critique sont priées de s'adresser à:

$$
\begin{gathered}
\text { Guillaume Fréchette } \\
\text { Philosophiques }
\end{gathered}
$$

Département de philosophie

Université du Québec à Montréal

c.p. 8888 , succ. Centre-ville

Montréal, Qc

H3C 3P8

frechette.guillaume@uqam.ca 